\title{
FORMAÇÃO CONTINUADA E SUAS IMPLICAÇÕES: ENTRE A LEI E O TRABALHO DOCENTE
}

\author{
Lígia Karam Corrêa de Magalhäes* \\ Leny Cristina Soares Souza Azevedo**
}

\begin{abstract}
RESUMO: Este artigo discute questóes relativas à formação de professores, com ênfase na formação continuada, a partir da análise das Metas 15 e 16 do Plano Nacional de Educação - PNE 2014-2024, anexo à Lei 13005/14, evidenciando a influência da LDB 9.394/96, das Diretrizes Curriculares Nacionais para a Formação de Professores da Educação Básica, em nível superior, curso de licenciatura, de graduação plena e da Rede Nacional de Formação Continuada de Professores. Nossa análise está ancorada no pressuposto de que a formação continuada é condição necessária no processo de formação ao longo da carreira, mas náo suficiente para o pleno exercício da docência garantida pela formação inicial de qualidade. Defendemos que o trabalho docente afiance ao professor autonomia em suas práticas pedagógicas, voltadas para o desenvolvimento intelectual, cultural e científico, de caráter emancipatório, buscando superar a concepção dualista e economicista da educação.
\end{abstract}

Palavras-chave: Formação continuada. PNE. Políticas educacionais. Trabalho docente.

\footnotetext{
* Universidade Federal do Rio de Janeiro, Faculdade de Educação, Rio de Janeiro, RJ., Brasil. E-mail de contato: ligiakaram@gmail.com

** Universidade Federal do Rio de Janeiro, Faculdade de Educação, Rio de Janeiro, RJ., Brasil. E-mail de contato: leny.az@hotmail.com
} 


\title{
Continuing education and its implications: between the law and the teaching work
}

\begin{abstract}
This article discusses issues related to teacher training, with emphasis on continuing education, based on the analysis of Targets 15 and 16 of the National Education Plan - PNE 2014-2024, appended to Law 13005/14, showing the influence of LDB 9.394/96 (the law that regulates Education in Brazil), the National Curricular Guidelines for the Formation of Basic Education Teachers in upper level undergraduate programs, full degree, and the National Network of Continuing Teacher Education. Our analysis is anchored on the assumption that continuing education is a necessary condition in the training process throughout a career, but not enough for the full exercise of teaching given by an initial quality training. We argue that the teaching work should guarantee the teacher's autonomy in his/her teaching practices, aimed at intellectual, cultural and scientific development, of an emancipatory nature, in search of overcoming the dualistic and economic conception of education.

Keywords: Continuing education. PNE. Educational policies. Teaching activity.
\end{abstract}

\section{INTRODUÇÃO}

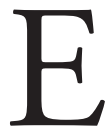

ste artigo discute questóes relativas à formação de professores, buscando aprofundar a discussão acerca da educação brasileira.

Enfatiza a formação continuada, a partir da análise das Metas 15 e 16 do Plano Nacional de Educação (PNE), anexo à Lei n. 13.005/14 aprovada em 25 de junho de 2014 (BRASIL, 2014), considerando a importância desse documento que legisla sobre a educação Nacional para os próximos dez anos, em consonância com a Lei de Diretrizes e Bases da Educação Nacional n. 9.394/96 (LDB) (BRASIL, 1996), as Diretrizes Curriculares Nacionais para Formação de Professores da Educação Básica, em nível superior, curso de licenciatura, de graduação plena (Diretrizes) (BRASIL, 2001), a Rede Nacional de Formação Continuada de Professores (BRASIL, 2004), além do farto material divulgado nas 
páginas do Ministério da Educação (MEC), com referência explícita ao tema em tela.

No Brasil sustentamos grande percentual dos professores da Educação Básica sem formação adequada. Segundo o Observatório do $\mathrm{PNE}^{1} 74,8 \%$ de professores que atuam na Educação Básica possuem curso superior, mas apenas 32,8\% que atuam nos anos finais do Ensino Fundamental e 48,3\% dos que lecionam no Ensino Médio "[...] tem licenciatura na área em que atuam [...]". Essa triste realidade vem na contramão do legislado, que almeja a formação específica em nível superior, a todos os professores, além de garantia da formação continuada.

Nossa análise está ancorada no pressuposto de que a formação continuada seja oferecida aos professores como atualização/complementação ao longo de sua carreira, constituindo-se em parte da organização do sistema de educação nacional sem, contudo, prescindir de que a formação inicial confira aos futuros professores "[...] a universalização de conhecimentos científicos explicativos dos processos naturais e da sociedade [...]". (LEHER, 2014)

Ocorre porém, que a formação continuada tem se dado em perspectiva mercadológica, enaltecendo modelos, na medida em que pressupóe o professor como executor, responsável pelo preparo de alunos para o mercado de trabalho, na perspectiva do novo desenvolvimentismo, conforme discute Motta (2009), estabelecendo uma "nova pedagogia da hegemonia" (NEVES, 2005), onde "[...] o aparelho escolar também (assim como os meios de comunicação) tem tido um papel pedagógico fundamental na conformação do novo homem coletivo requerido pelo neoliberalismo da Terceira Via [...]". ${ }^{2}$ A autora aponta que as reformas educacionais postas em prática

[...] alteram substantivamente as funçóes econômicas e político-sociais da escola brasileira [...]. Essas reformas têm por finalidade formar, no espaço nacional, intelectuais urbanos de novo tipo, ou seja, especialista e dirigentes que, do ponto de vista técnico, possam aumentar a competitividade e produtividade do capital, nos marcos do capitalismo periférico [...]. (NEVES, 2005, p.104) 
Nesse sentido, os professores têm sido, cada vez mais, destituídos de autonomia que lhes permita refletir, criar, inovar o processo de ensino-aprendizagem junto a seus alunos e a partir de contextos próprios.

Com base no exposto, organizamos o texto em partes integradas que conferem organicidade à reflexão, iniciando pelas conjunturas econômica, política e social da educação nacional e, mais especificamente, da formação de professores a partir da década de 1990 aos dias atuais. $\mathrm{Na}$ segunda parte, discutimos a formação continuada: conceituação, avanços e permanências; e, na terceira e última parte, tecemos considerações finais, apontando algumas implicaçôes da formação continuada no/ para o trabalho docente.

\section{FORMAÇÃO CONTINUADA DE PROFESSORES: QUESTÕES ECONÔMICAS, POLÍTICAS E SOCIAIS E O PNE}

Na década de 1990, mais precisamente a partir de 1995, as políticas educacionais fazem referência a uma "nova ordem mundial", naturalizada no discurso da globalizaçáo, ao apregoar um novo imperialismo com a reestruturação produtiva: novas formas de ordenação econômica, a reconfiguração do Estado pela redefinição de suas funçóes e a "revolução" possibilitada pelas tecnologias da informação e da comunicação. Nesse contexto, a "sociedade da informaçáo"; as parcerias público privadas; a mercantilizaçáo da educação, em que cursos de formaçáo passam a ser terceirizados e/ou oferecidos virtualmente, muitas vezes com a participação da iniciativa privada, trazendo para o ensino a lógica do mercado, com o deslocamento da educação para o setor de serviços; assim como a ressignificação e a relexicalização das categorias trabalho e educação, ocupam lugar de destaque no discurso, em geral, e no discurso pedagógico em particular.

Nesse novo cenário mundial,

[...] caracterizado como um patamar superior do capitalismo monopolista, no qual o conteúdo e a forma de organização do trabalho e da produção, bem como 
as relaçôes de poder e as relaçôes sociais, foram particularmente alterados [...]. (OLIVEIRA, 2011, p. 91)

ocorreram mudanças nas políticas públicas no âmbito educacional que interferiram na formação docente, cujas implicaçóes estão presentes no trabalho docente desenvolvido em todos os níveis de ensino, com destaque na Educação Básica.

Assim, as reformas na educação como um todo, e para a formação de professores em especial, estão materializadas nos documentos que legitimam a educação nacional. Dentre estes, a LDB dedica os artigos 61 a 65 do Título VI - Dos Profissionais da Educação, trazendo mudanças importantes no contexto da formação dos profissionais da educação, ao salientar que a formação se faça em "cursos reconhecidos". A categoria trabalho perde aqui seu lugar para "atividades", com destaque para o parágrafo único do Art. 61:

A formação dos profissionais da educação, de modo a atender às especificidades do exercício de suas atividades, bem como aos objetivos das diferentes etapas e modalidades da educação básica, terá como fundamentos:

I - a presença de sólida formação básica, que propicie o conhecimento dos fundamentos científicos e sociais de suas competências de trabalho;

II - a associação entre teorias e práticas, mediante estágios supervisionados e capacitação em serviço;

III - o aproveitamento da formação e experiências anteriores, em instituiçóes de ensino e em outras atividades. (BRASIL, 1996) (Grifos das autoras).

Os grifos enfatizam a precarização da formação, com implicaçôes para o trabalho docente, ao centrar a formação na pedagogia das competências, cujos atributos são utilitaristas, na medida em que caracteriza o trabalho do professor como forma de administrar as práticas pedagógicas, atribuindo-lhe o lugar de "tarefeiro" (KUENZER, 1999) 
e contribuindo para um novo perfil de homem, consoante com a "nova ordem mundial”: flexível, adaptável às novas e constantes mudanças. A autora levanta que existem

[...] modelos (de educação) que se diferenciam, dadas as concepçóes de educação e de sociedade que correspondem às demandas de formaçáo dos intelectuais [...] demandas de formaçáo de professores respondem a configuraçôes que se originam nas mudanças ocorridas no mundo do trabalho e nas relaçóes sociais, e a configurações oriundas das diferentes posições que sáo assumidas em relação aos projetos apresentados pelo grupo que ocupa o poder a partir de determinada correlação de forças. (KUENZER, 1999, p. 166)

Portanto, centrar a formação docente no desenvolvimento de competências e na capacitação mostra o caráter do ensinar a fazer, naturalizando o sentido singular possibilitado por modelos que chegam às escolas através de programas/projetos do "como fazer o ensino". Aqui são apagados os contextos plurais.

O efeito tende a ser o esvaziamento do trabalho docente e a construção de uma imagem de professor caracterizada pela negação da sua condição de intelectual organizador da cultura. (GRAMSCI, 1991)

Corroborando o debate da precarização, Leher (2104) aponta que

[...] a expansão da oferta da escola pública nos países capitalistas dependentes - uma realidade na educação básica e em certas modalidades de educação profissional - está sendo acompanhada de drástico esvaziamento de seu conteúdo científico, histórico-cultural, tecnológico e artístico.

Ao discutir sobre a escola como princípio educativo, Gramsci (1991, p. 131) afirma que "[...] na escola, o nexo instrução-educação somente pode ser representado pelo trabalho vivo do professor [...]". Nesse sentido entendemos que tanto a formação inicial quanto a continuada 
devam considerar o trabalho do professor como sendo "consciente dos contrastes", para além de uma formação pautada em competências, em programas de qualificação, levando às escolas materiais prontos, maximizados pelas tecnologias cada vez mais presentes no ensino. $\mathrm{O}$ autor chama atenção para a situação da precariedade na formação dos professores, ao destacar que "Com novos programas, que coincidem com uma queda geral do nível do corpo docente, simplesmente não existirá mais 'bagagem' a organizar [...]” (p. 132). Sobre a participação ativa do aluno, assinala que essa "só pode existir se a escola for ligada à vida" (p. 133).

Dessa forma, a educação de qualidade, em perspectiva emancipatória, com vistas a formar professores e alunos como sujeitos investidos de autonomia, se encontra comprometida. E é nesse sentido que resgatamos o conceito de autonomia em Freire (1996), como princípio pedagógico para uma educação libertadora. Educação essa que propicie as necessárias condiçóes à professores e educandos no desenvolvimento de sua subjetividade, de representaçóes de mundo, de construção e defesa de argumentos a partir de sua visão de mundo. Para o autor, "formar é muito mais do que puramente treinar o educando no desempenho de destrezas [...]" (p. 14) (grifos das autoras). "[...] é no domínio da decisão, da avaliação, da liberdade, da ruptura, da opção, que se instaura a necessidade da ética e se impóe a responsabilidade [...]" (p. 18).

Com isso, o autor explicita a participação de professores e educandos na "construção da própria presença" (p. 19) no processo de ensino-aprendizagem, assinalando a necessária ruptura com o "já dado" e, assim, criando possibilidades a partir dos sujeitos e do contexto em que acontece a prática docente:

[...] ensinar não é transferir conhecimentos, conteúdos nem formar é ação pela qual um sujeito criador dá forma, estilo ou alma a um corpo indeciso e acomodado. Não há docência sem discência, as duas se explicam e seus sujeitos apesar das diferenças que os conotam, não se reduzem à condição de objeto, um do outro [...]. (FREIRE, 1996, p. 23)

Salientamos que a demanda pela continuidade da formação ao longo do exercício profissional só encontra sentido uma vez alcançada 
a autonomia conforme nos lega Freire, pois, de outra forma, como dar continuidade ao que não existe?

Outro documento em debate são as Diretrizes. Ao estabelecerem um novo perfil docente, centrado no desenvolvimento de competências, em cursos que enaltecem a prática em detrimento da teoria, ao defender a noção de "simetria invertida" o que, entre outros aspectos,

[...] evidencia a necessidade de que o futuro professor experiencie, como aluno, durante todo o processo de formaçáo, as atitudes, modelos didáticos, capacidades e modos de organização que se pretende venham a ser concretizados nas suas práticas pedagógicas [...]. (BRASIL, 2001, p.30-31)

O terceiro documento em destaque é o PNE 2014-2024, com foco nas Metas 15 e 16, por tratarem da questão da formação inicial e continuada de professores. O texto corrobora com questóes discutidas nos documentos acima ao optar por modelos de formação docente que "valorize $[\mathrm{m}]$ a experiência prática", como expresso na estratégia 15.3, retomando a lógica de valorização dos "saberes da experiência" em detrimento de conhecimentos da área de atuação profissional.

O processo de formaçáo continuada presente mais largamente nas Metas 15 e 16 encontram-se organizadas na primeira em 13 estratégias, buscando:

Garantir, em regime de colaboração entre a Uniāo, os Estados, o Distrito Federal e os Municípios, no prazo de 1 ano de vigência deste PNE, política nacional de formação dos profissionais da educação de que tratam os incisos I, II e III do caput do art. 61 da Lei no 9.394, de 20 de dezembro de 1996, assegurado que todos os professores e as professoras da educação básica possuam formação específica de nível superior, obtida em curso de licenciatura na área de conhecimento em que atuam. (BRASIL, 2014) 
E, na segunda em seis estratégias voltadas para

Formar, em nível de pós-graduação, 50\% (cinquenta por cento) dos professores da educação básica, até o último ano de vigência deste PNE, e garantir a todos (as) os (as) profissionais da educação básica formação continuada em sua área de atuação, considerando as necessidades, demandas e contextualizaçóes dos sistemas de ensino. (BRASIL, 2014)

Juntas, essas Metas propóem diversas ações, legislando sobre os modelos de formação inicial e continuada, a valorização da carreira do magistério, o processo de mercantilização da formação para o trabalho docente, mas, conforme apresentam Piccinini et al. (2014, p. 1586)

[...] abrem caminho para que novas diretrizes curriculares sejam postuladas a partir de antigos, e de novos, interesses expressos no Plano. A definiçáo de áreas prioritárias para os investimentos e processos de formação, por exemplo, permite antever tensôes e embates sobre o sentido da formação para o trabalho docente.

A estratégia 16.1 do PNE, por exemplo, prevê o dimensionamento da demanda por formação continuada em regime de colaboração (Federal, Estadual e Municipal), contudo, nada é dito sobre as formas e em que condiçóes se fará a formação continuada.

Vale destacar que, ao longo do documento como um todo, a iniciativa privada está fortemente presente, deflagrando o empreendedorismo da educação, o que endossa o novo desenvolvimentismo apontado no início deste trabalho.

O discurso do MEC enaltece a educação de professores, conferindo ênfase à formação continuada também:

1. em outros Artigos da LDB: Art. 63, manutenção de “[...] programas de educação continuada para os profissionais de educação dos diversos níveis [...]"; Art. 67 "[...] promoção da 
valorização dos profissionais da educação [...] aperfeiçoamento profissional continuado [...]" e, o Art. 80, que abre caminho para que o ensino a distância também seja um caminho para a formação continuada;

2. no Parecer no CNE/CP 009/2001 (BRASIL, 2001), que fundamenta as Diretrizes, a formaçáo continuada aparece como atendimento "[...] a formaçáo (que) deva ser complementada ao longo da vida [...]" (p.9); ao endossar os artigos da LDB que fazem referência à "relação entre teoria e prática" e no "aproveitamento da experiência anterior”, ao construir aprendizagens significativas junto aos futuros alunos; e, oferta de "programas de educação continuada" (p.14). Ao finalizar traz que "E ainda no momento de definição da estrutura institucional e curricular do curso que caberá a concepção de um sistema de oferta de formação continuada que propicie oportunidade de retorno planejado e sistemático dos professores às agências formadoras [...]" (p.58);

3. nas Metas $1,3,4,5,7,10$ onde a formação continuada está presente quer promovendo a formação, incentivando práticas pedagógicas estruturadas a partir da relação teoria/prática, quer repensando currículos, ampliação de vagas e outros.

Além desses documentos, que conformam a educação nacional, merece destaque a Rede Nacional de Formaçáo Continuada de Professores (BRASIL, 2004), “[...] criada em 2004, com o objetivo de contribuir para a melhoria da formação dos professores e alunos. $\mathrm{O}$ público-alvo prioritário da Rede são professores de Educação Básica dos sistemas públicos de educação [...]”.

O que chama atenção nos estudos e pesquisas de cunho crítico é a contradição entre o dito (legislado) e o visto (resultados); entre o que tem sido propalado - como a necessidade de oferta de educação de qualidade aos futuros professores -, e os programas de Formação Continuada apresentados no site do $\mathrm{MEC}^{3}$ : Formação no Pacto Nacional pela Alfabetização na Idade Certa; ProInfantil; Plano Nacional de Formação de Professores da Educação Básica; Proinfo Integrado; e-Proinfo; Pró-letramento; Gestar II; Rede Nacional de Formaçáo Continuada de Professores. Sobre os vários Programas oferecidos, Gatti (2008) nos ajuda a elucidar que 
[...] muitas das iniciativas públicas de formação continuada no setor educacional adquiriram, então, a feição de programas compensatórios e náo propriamente de atualização e aprofundamento em avanços do conhecimento, sendo realizados com a finalidade de suprir aspectos da má-formação anterior, alterando o propósito inicial dessa educação - posto nas discussóes internacionais - , que seria o aprimoramento dos profissionais nos avanços, renovações e inovaçóes de suas áreas [...]. (GATTI, 2008, p. 58)

De acordo com a ideologia das políticas de formação de professores, Evangelista e Shiroma (2004, p.535) levantam a hipótese de que

[...] a política de profissionalização de professores e gestores, nos moldes em que vem sendo implantada, tem por objetivo não o aumento da qualificação do quadro do magistério, mas, sim, a sua desintelectualização para, desse modo, torná-los pragmáticos, diminuindo-lhes a capacidade de intervenção consciente $[\ldots]$.

Retomamos em Gramsci (1991) o conceito de dualidade escolar na discussão sobre a escola interessada e a escola desinteressada, de suas reflexóes sobre a escola como instrumento para elaborar os intelectuais de diversos meios; e sobre o papel do educador como intelectual orgânico das camadas populares, comprometido com a transformação das atuais condiçốes políticas, econômicas e sociais.

A dualidade escolar caracteriza-se pela coexistência de projetos de educação diferenciados para classes sociais distintas, a serviço da manutenção da ordem social hegemônica, assegurando a função reprodutora da atividade educacional. (MAGALHÁES, 2008) A tessitura das políticas educacionais trazidas nessa primeira parte subsidia a discussão sobre avanços e permanências no processo da formação continuada, como veremos a seguir. 


\section{FORMAÇÃO CONTINUADA DE PROFESSORES: “LEITURAS E ESCUTAS" QUE PERSISTEM}

Nos últimos anos, observamos que se tem fortificado, no panorama pedagógico brasileiro, o olhar na formação docente. Esse fato pode ser constatado no reforço da ideia de que uma política de formação não deve coexistir a partir de ações isoladas e fragmentadas, que não reformulem a concepção de práticas pedagógicas concebidas através de cursos com atividades múltiplas e dissociadas da produção de conhecimentos.

Contudo, observamos com frequência o agravamento das condições de ensino em nosso país, especialmente no que se refere à formação docente inicial e continuada - resultado de uma política educacional autoritária, que tem sido criticada em diversos encontros, congressos, publicaçóes e reunióes de educadores. Todo esse esforço carece de articulação e compreensão, principalmente das amarras e armadilhas legais, a fim de que os educadores possam unificar as lutas em prol da democratização do ensino. Diante disso, questionar a amplitude de formação continuada pode reanimar o debate e difundir a perspectiva crítica, como esclarece Gatti, quando reflete a respeito da concepção dessa formação:

[...] sinalizamos que ora se restringe aos limites de cursos estruturados e formalizados oferecidos após a graduação, ou após ingresso no exercício do magistério, ora é tomado de modo amplo e genérico, como compreendendo qualquer tipo de atividade que venha a contribuir para o desempenho profissional - horas de trabalho coletivo na escola, reunióes pedagógicas, trocas cotidianas com os pares, participação na gestáo escolar, congressos, seminários, cursos de diversas naturezas e formatos, oferecidos pelas Secretarias de Educação ou outras instituiçóes para pessoal em exercício nos sistemas de ensino, relaçóes profissionais virtuais, processos diversos, enfim tudo que possa oferecer ocasião de informação, reflexão, discussão e trocas que favoreçam o aprimoramento profissional, 
em qualquer de seus ângulos, em qualquer situação. (GATTI, 2008, p. 57)

Diante disso, ao analisar a prática docente destacam-se diferentes aspectos que despertam o interesse para o questionamento de algumas orientaçóes acerca da formação continuada e a importância de seu papel na valorização e transformação do ensino, ao buscar conhecer como o professor é formado nas e pelas instituiçóes escolares e como essa formaçáo se relaciona à sua prática profissional. Sem perder o fio da meada e em nome de discutir alternativas, acreditamos ser pertinente trazer as indagaçóes proferidas em 2014, por Eveline Algebaile ${ }^{4}$, sobre:

a) O que acontece quando os docentes são submetidos à necessidade de formação?

b) O que ocorre quando são convencidos de que lhes falta algo?

Com essas perguntas, verifica-se o discurso de que a responsabilidade das lacunas no sistema de ensino é dos docentes, pela ausência de uma formação adequada. Nesse processo, aponta-se para a submissão de um planejamento feito, muitas vezes, longe do dia a dia das práticas e problemáticas das salas de aula, o que impede a articulação da formação dos profissionais a partir de uma série de conhecimentos que podem ser acionados no curso do exercício da profissão. Esses conhecimentos, direcionados, poderiam efetivar a integração entre educação e trabalho, articulando saberes e fazeres provenientes de diferentes campos de atuação e de experiências que, via de regra, são diversificadas.

A singularidade das situações da prática profissional é enfatizada, objetivando-se focalizar de modo superficial a crença de que problemas da prática possam ser resolvidos pela simples aplicação de conhecimentos científicos ou de técnicas deles derivadas. Os ditames da formação em serviço acabam ocultando uma prática social de intervenção mais abrangente, para o alcance de outros espaços da vida da sociedade. Severino (2003) explica que, quando se fala na formação do educador é preciso clarear bem a questão, pois não se trata apenas da sua habilitação técnica, da aquisição e do domínio de um conjunto de informaçóes e de 
habilidades didáticas. Impõe-se ter em mente a formação no sentido da formação humana em sua integridade, pois

[...] a complexidade da funçáo social e profissional do educador implica muito mais, em termos de condiçóes pessoais, do que outras profissóes nas quais a atividade técnica do profissional tem uma certa autonomia em relação à sua própria qualificação pessoal. (SEVERINO, 2003, p. 75)

Concordamos que esse perfil é importante para que seja fecunda a atividade educativa do docente, juntamente com o amadurecimento de sua personalidade e sua condição pessoal, buscando atingir a efetivação dos seus objetivos nos planos científico e pedagógico, para que seja profícua a incorporaçáo dos processos de produção de conhecimento.

Lembramos que o profissional empresta sua experiência às regularidades do seu ofício e, quando se destaca a formação continuada, os estudos têm mostrado a importância das experiências prévias na constituiçáo da profissionalidade, por estarem esses docentes inseridos em instituiçôes escolares por um longo período e apresentarem conceitos e representaçóes sobre o ensino e sobre o papel do professor. Essas experiências prévias podem e devem, em nosso entender, ser trabalhadas como um aspecto singular na trajetória do docente e abordadas como algo que pode facilitar ou dificultar a construção de novas concepçôes, novas atitudes e valores sobre a docência.

Para alguns estudiosos da formação docente, o ensino pode ser entendido como um ofício que se apoia em saberes construídos pela experiência acumulada na prática social e coletiva dos professores. De acordo com Sacristán (1999), o saber fazer profissional está relacionado com a condução da prática escolar e se desenvolve por meio dos esquemas práticos, que se constituem em modelos de atividades de ensino, ligadas a um determinado conteúdo. Os esquemas práticos não são esquemas prontos que o professor coloca mecanicamente em ação na sua atividade profissional. $\mathrm{O}$ docente, ao longo de sua carreira, cria ou se apropria de diferentes esquemas práticos, modifica-os ou combina-os de maneira nova. Para compreender o próprio processo de constituição 
desses esquemas, é preciso, entre outras coisas, compreender a relação entre pensamento e açáo para todos os envolvidos no processo de ensino-aprendizagem: docentes e estudantes.

Para Sacristán (1999) os saberes da experiência não se apresentam como um corpo sistematizado de conhecimento, mas são partes constituintes da prática, formando um conjunto de representaçóes a partir das quais o professor interpreta, compreende e orienta sua profissão e sua prática cotidiana em todas as dimensóes.

Outras pesquisas sobre o tema associam os projetos de formação continuada com a política de capacitação docente, elaborada pelos órgãos oficiais. Ao se fazer uma revisão crítica, os debates dão mostra de que se encontram no pressuposto básico desses programas algumas metas para reverterem à situação limítrofe do ensino público. Isso significa que existe a ênfase diretamente relacionada à preparação do professor e um discurso nas entrelinhas sobre sua incompetência, que vai sendo sedimentada pelos programas e projetos de capacitação reducionistas, os quais obtêm legitimação através deste mesmo discurso. (SOUZA, 2006; FERREIRA, 2003; CANDAU, 1996; ARROYO, 1996) É assim que muitos cursos presenciais ou não, são justificados e destacamos a abordagem abaixo que elucida nossa posição, pois,

[...] é muito presente em nosso meio a crença de que basta o profissional da educação dominar e aplicar competentemente a sua atividade docente, determinadas habilidades técnicas, para que a relação pedagógica surta seus efeitos, independentemente de qualquer outra significação que não aquela funcionalmente implícita no puro conhecimento objetivo produzido pelas ciências. (SEVERINO, 2003, p. 86)

Esse trecho nos remete à prevalência da crítica ao tecnicismo e Gatti (2008, p. 63), chama a atenção para o fato de que uma "[...] técnica também pode ser usada em contexto de ambiência não necessariamente tecnicista, e ao contrário, compor-se em um conjunto com intencionalidade transformadora [...]". Entretanto, ressaltamos as nossas preocupaçóes quanto aos programas e cursos que buscam acrescentar 
na formação básica ou continuada algumas competências e habilidades enunciadas como ingredientes "rotulados".

Considerando essas discussōes, vale dizer que não é possível desconhecermos a precariedade da formação de parte do corpo docente das escolas fundamentais e médias, assim como parte do corpo docente de universidades, mas é pertinente interrogar o quanto essa precariedade tem sido propagandeada nos discursos feitos pela mídia e, principalmente, indagar com que intencionalidade.

Entretanto, com os desdobramentos das legislaçóes e aprovaçáo de diversos dispositivos legais, a formação continuada vem sendo implementada, buscando o desenvolvimento profissional docente, estabelecendo parcerias com universidades, com os sistemas de ensino público, com Centros de Pesquisa e Desenvolvimento da Educação, contando com a coordenação do MEC/SEB 5 . Dessa forma, à profissionalização vinculou-se a necessidade de efetivar a qualidade da educaçáo, sintonizando-as com as orientações dos organismos internacionais.

Exemplos disso são os documentos do Banco Mundial (BM) explorados por Gatti (2008) que focalizam o caráter renovador da formação, face aos insucessos do sistema educativo. As articulaçóes com o $\mathrm{BM}$ e outras organizações internacionais se fundem e se confundem com propósitos democráticos, e um olhar mais atento evidencia a condução de políticas educacionais que confirmam os efeitos desmobilizadores que impóem prescriçóes à formação docente e ao processo de reestruturação neoliberal no Brasil. (DE ROSSI, 2001) Entendemos não ser por acaso que os documentos internacionais indicam que a formação das novas geraçóes deve se orientar para a nova economia mundial. Assim, a finalidade da educação deve ser aumentar a produtividade e, nessa perspectiva desenvolver atividades para a participação no mercado de trabalho e na sociedade. Fundamentam-se essas orientaçóes internacionais preconizadas na década de 1990, e estendidas as décadas subsequentes no entendimento da educaçáo como um recurso para o crescimento do capital como forma de produção de vida material na sociedade mundializada. (SOUZA; RAMALHO, 2012)

Desse desfecho resulta que a educação é concebida como um investimento em capital humano individual, que habilita os indivíduos 
para a competição pelos empregos disponíveis. O professor, assim, é instado a produzir mais, competir mais, o que se torna possível com "[...] a incorporação de inovaçôes tecnológicas que permitem reduzir o tempo de trabalho pago, aumentando, consequentemente, o tempo de trabalho não pago, pois assim maior será a produtividade do trabalho [...]”. (SAVIANI, 2007, p. 191)

Convém ressaltar que, embora a LDB tenha incorporado em seus artigos as exigências dos educadores quanto à formação continuada de professores, entendemos que essa Lei atende a inspiração neoliberal que possibilita pactos conciliatórios entre outros agentes e, assim, de acordo com De Rossi (2001), está envolta de algumas iniciativas, tais como: o empenho em reduzir custos, encargos e investimentos públicos, buscando transferi-los e/ou dividi-los com a iniciativa privada e organizações não-governamentais.

Diante disso, afirmamos que a formação de um docente não se faz acumulando cursos, conhecimentos ou técnicas - apesar de serem acréscimos positivos -, mas sim pela reflexão do trabalho educativo e sua identidade pessoal e profissional, levando em conta as dificuldades na busca do significado no interior de suas aprendizagens ou do que aprende com suas práticas. Para De Rossi (2001, p. 95),

[...] tais práticas contribuem para organizar algo que hoje tem encontrado pouco espaço: as bases do procedimento político e a essência da política, entendida como a organização da esfera pública na qual as pessoas ampliam sua comunicação, articulam suas opinióes e se unem para alcançar objetivos coletivos e interesses comuns.

Com base nesse trecho, esclarecemos que os fundamentos das práticas relacionam-se a padróes de complexidade em constante transformação. Para que os professores se engajem em tal debate, faz-se necessário o desenvolvimento de uma perspectiva teórica, redefinindo a crise educacional e, ao mesmo tempo, fornecendo as bases para uma visão alternativa para o aprimoramento e trabalho dos educadores/ 
profissionais do magistério. Em síntese, compartilhamos com Giroux (1997, p. 158) a compreensão de que,

O reconhecimento que a crise na educação tem muito a ver com a tendência crescente de enfraquecimento dos professores em todos os níveis da educação é uma precondição teórica necessária para que eles efetivamente se organizem e estabeleçam uma voz coletiva no debate educacional atual.

\section{CONSIDERAÇÕES FINAIS}

O que pretendemos demarcar é que, nos anos 1990, políticas para formação continuada foram ampliadas, através dos textos legais das reformas, com diretrizes que tratam essa qualificação docente como prioridade, sendo possível reconhecer as influências dos discursos internacionais nessa formação. Uma formação profissional que, de acordo com Oliveira (2007), requer renovaçóes institucionais, metodológicas, teóricas, ético-morais e mecanismos de divulgação do conhecimento.

Postulamos que a formação continuada não deve suprir a formação inicial, base para o exercício profissional com qualidade, conferindo aos cidadãos as múltiplas possibilidades de ocuparem seu lugar na sociedade de forma engajada, na tomada de decisóes e na luta por mudanças que coletivamente se fazem prementes na construção da nação.

Nossa defesa é a de que a formação continuada, inerente a todo profissional, não importando a área de atuação, é parte do processo de formação ao longo da carreira, na medida em que acompanhar pesquisas, produçóes teóricas do campo, realizar novos cursos, inovar práticas pedagógicas, a partir do contexto em que atuam os professores, constituem procedimentos que complementam a formação inicial. Esta deveria estar presentes quer em cursos formais quer em informais, suprindo distanciamentos teórico/práticos/metodológicos, advindos da produção de novos conhecimentos nas mais diversas áreas, em resposta às demandas econômica, social, tecnológica e cultural da humanidade. 
Em nosso estudo, depreendemos que a continuidade se apresenta em dois sentidos: o primeiro, mais referido, como a formação continuada onde ocorre a proximidade do profissional com a atualização/ capacitação/treinamento dos estudos, enquanto que o segundo, menos contemplado, é o trabalho continuado, ou seja um fazer do professor que perpetua o processo de ensinar o necessário para que seja aprendido o requerido pelo mercado de trabalho, caracterizando um ensino inscrito nas tendências pedagógicas liberais ou conforme classifica Saviani (1985) como não críticas.

O primeiro (sentido) está coadunado com o discutido em Kuenzer (1999), para quem as propostas de formação se fazem na perspectiva de formar o professor "tarefeiro", enquanto que o segundo está afeto ao desenvolvimentismo discutido em Motta (2009, p. 553), em que "[...] a escola continuou sendo vista como importante investimento para o desenvolvimento do 'capital humano individual', [...] como potencial de inserção no mercado [...]”. E mais adiante, Motta afirma que nessa perspectiva "Operam-se, assim, mecanismos de despolitização e conformação com as condiçóes impostas pelo grande capital, indo para além de educar para a sobrevivência, educando para a conformaçáo [...]" (p. 563).

Urge o diálogo para o enfrentamento das questóes cotidianas das escolas, não se podendo desconsiderar as experiências docentes, os seus modos de fazer, seus desejos, aspiraçóes e, sobretudo, buscando compreender como circulam as práticas, os conhecimentos e as mediações pedagógicas nas salas de aula. Ter em pauta a condição profissional no percurso da formaçáo inicial e continuada dos professores implica a possibilidade de investir na leitura e na escuta da constituição e fortalecimento da identidade profissional docente. Significa para nós, como nas palavras de Milton Santos (1998, p. 15) que "[...] o trabalho do educador, do professor tornado educador, seja o trabalho de interpretação do mundo, para que um dia este mundo não nos trate mais como objetos e para que sejamos povoadores do mundo como homens [...]”. 


\section{REFERÊNCIAS}

ARROYO, M. G. Reinventar e formar o profissional da educação básica. In: BICUDO, M. A., SILVA JUNIOR, C. (Orgs.). Formação do Educador. v. 1, São Paulo: UNESP, 1996, p. 47-67.

BRASIL. Lei no 13.005, de 25 de junho de 2014. Aprova o Plano Nacional de Educação - PNE e dá outras providências. Diário Oficial [da] República Federativa do Brasil, Brasília, 26 jun. 2014. [Edição extra - seção 1].

BRASIL. Rede Nacional de Formação Continuada de Professores da Educação Básica: orientaçôes gerais. 2004. Disponível em <http://www.oei.es/quipu/ brasil/Red_Nac_form_continua.pdf>. Acesso em 10 dez. 2011.

BRASIL. MEC/CNE/CP. Parecer no 009, de 08 de maio de 2001. Diretrizes Curriculares Nacionais para a Formação de Professores da Educação Básica, em nível superior, curso de licenciatura, de graduação plena. Brasília/DF, 08/05/2001.

BRASIL. Lei 9.394, de 1996. Regulamenta as Diretrizes e Bases da Educação Nacional. Diário Oficial [da] República Federativa do Brasil, Brasília, 1996.

CANDAU, V. M. Formação continuada de professores: tendências atuais. In: REALI, A. M. M. R.; MIZUKAMI, M. G. N. (Orgs.). Formaçẫo de professores: tendências atuais. São Carlos: EDUFSCAR, 1996.

DE ROSSI, V. Desafio à escola pública: Tomar seu destino em suas próprias mãos. Cadernos Cedes, ano XXI, n. 55, novembro/2001.

EVANGELISTA, O., SHIROMA, E. O. A colonização da utopia nos discursos sobre profissionalização docente. PERSPECTIVA, Florianópolis, v. 22, n. 02 , jul./dez, 2004, p. 525-545.

FERREIRA, N. S. C. Formação continuada e gestão da educação na "cultura globalizada". In: FERREIRA, N. S. C. Formaçẫo continuada e gestão da educação. 3. ed. São Paulo: Cortez, 2007.

FREIRE, P. Pedagogia da autonomia: saberes necessários à prática educativa. 7. ed. Rio de Janeiro: Paz e Terra, 1996.

GATTI, B. A. Análise da política públicas para formação continuada no Brasil, na última década. Revista Brasileira de Educação, Rio de Janeiro, Anped; v. 13, n. 37, p. 57-70, jan./abr. 2008.

GIROUX, H. Os professores como intelectuais: rumo a uma pedagogia crítica da aprendizagem. Porto Alegre: Artes Médicas, 1997. 
GRAMSCI, A. Os intelectuais e a organização da cultura. 8. ed. Rio de Janeiro: Civilização Brasileira, 1991.

KUENZER, A. Z. As políticas de formação: a constituição da identidade do professor sobrante. Educ. Soc., Campinas, v. 20, n. 68, p.163-183, dez. 1999.

LEHER, R. Organização, Estratégia Politica e o Plano Nacional de Educação. Disponível em: <http://marxismo21.org/wp-content/ uploads/2014/08/R-Leher-Estrat\%C3\%A9gia-Pol\%C3\%ADtica-e-PlanoNacional-Educa\%C3\%A7\%C3\%A3o.pdf>. Acesso em: 02 fev. 2015.

MAGALHĀES, L. K. C. Formação e trabalho docente: os sentidos atribuidos às tecnologias da informação e da comunicação. 2008. 275f. Tese Doutorado em Educação, Faculdade de Educação, Universidade do Estado do Rio de Janeiro, Rio de Janeiro. 2008.

MOTTA, V. C. Ideologias do capital humano e do capital social: da integração à inserção e ao conformismo. Revista Trab. Educ. Saúde, v. 6, n. 3, p. 549-571, nov./fev. 2009.

NEVES, L. M. W. A sociedade civil como espaço estratégico de difusão da nova pedagogia da hegemonia. In: NEVES, L. M. W. (Orgs.). A nova pedagogia da hegemonia: estratégias do capital para educar o consenso. São Paulo: Xamã, 2005.

OLIVEIRA, D. A. Política educacional e a re-estruturação do trabalho docente: reflexões sobre o contexto latino-americano. Educ. Soc., v. 28, n. 99, p. 355-375. Campinas, 2007.

OLIVEIRA, D. M. As diretrizes técnicas e ético-políticas dos organismos internacionais para a formação de professores. In: ANDRADE, J., PAIVA, L. (Orgs.). As políticas para a educação no Brasil contemporâneo: limites e contradiçóes. Juiz de Fora: Ed. UFJF, 2011. p. 90-107.

PICCININI, C. et al. PNE e Trabalho Docente: formação, forma(ta)ção e (con) formação. In: JORNADA DO HISTEDBR E SEMINÁRIO DE DEZEMBRO: A crise estrutural do capitalismo e seus impactos na educação pública brasileira, 12, 2014, Caxias-Maranhão. Anais... Caxias, CESC, 2014. p.15851600. Disponível em: <http://www.xiijornadahistedbr.com.br/anais/anais. html>. Acesso em 6 dez. 2014.

SACRISTÁN, G. Poderes instáveis da educação. Porto Alegre: Artmed, 1999.

SANTOS, M. O professor como intelectual na sociedade contemporânea. In: XI ENCONTRO NACIONAL DIDÁTICA E PRÁTICA DE ENSINO: 
Olhando a qualidade do ensino a partir da sala de aula, Águas de Lindóia, Anais..., 1998. p.11-28.

SAVIANI, D. Doutoramento em educação: significado e perspectivas. Diálogo Educ., Curitiba: v. 7, n. 21, p.181-197, maio/ago. 2007.

SEVERINO, A. J. Preparação técnica e formação ético-política dos professores. In: BARBOSA, R. L. (Org.). Formação de educadores: desafios e perspectivas. São Paulo: UNESP, 2003. p. 71-89.

SOUSA, A. S. Q.; RAMALHO, B. L. Políticas de Formação de Professores no Brasil e a Modalidade à Distância: pontos para reflexôes. Revista Exitus, v. 02, n. 01, p. 45-55, jan./jun., 2012.

SOUZA, D. T. R. Formaçáo continuada de professores e fracasso escolar: problematizando o argumento da incompetência. Educ. Pesqu., São Paulo, v. 32, n. 3, p. 477-492, dec. 2006.

\section{NOTAS}

1. Fonte: MEC/Inep/DEED/Censo Escolar (Todos pela Educação). Disponível em: $<$ http://www.observatoriodopne.org.br/metas-pne/15-formacao-professores>. Acesso: 12 dez. 2014.

2. A política da Terceira Via busca um novo relacionamento entre indivíduo e a comunidade, uma redefinição de direitos e obrigaçóes. (GIDDENS, 2001, p. 75) Dentre os dogmas citados por Giddens (1999), está o da substituição da expressão "Estado do Bem-Estar" por "Sociedade do Bem-Estar", em que as parcerias do Estado com empresas, "sobretudo do setor (ou serviços)", o desobrigam de pagar os benefícios conquistados com anos de lutas pelos trabalhadores: o salário desemprego, a saúde e a educação pública gratuitas.

3. Disponível em: <http://mecsrv125.mec.gov.br/index.php?option=com_content\&vie $\mathrm{w}=$ article\&id $=18838 \&$ Itemid $=842>$. Acesso em 10 fev. 2015.

4. Conferência de abertura proferida pela professora Eveline Algebaile (UERJ/FFP) no Encontro organizado pelo Coletivo de Estudos Marxismo e Educação (Colemarx) da Faculdade de Educaçáo/UFRJ, set. 2013.

5. Disponível em: <http://portal.mec.gov.br/seb/arquivos/pdf/Rede/catalg_rede_06. pdf>. Acesso em: 9 dez. 2014.

Recebido em 06 de março de 2015. Aprovado em 11 de maio de 2015.

DOI: http://dx.doi.org/10.1590/CC0101-32622015146769 